\title{
The effect of levothyroxine treatment on left ventricular function in subclinical hypothyroidism
}

Valentina Velkoska Nakova', Brankica Krstevska², Elizabeta Srbinovska
Kostovska $^{3}$, Olivija Vaskova ${ }^{4}$, Ljubica Georgievska Ismail
1 University "Goce Delchev", Faculty of Medical Science, Clinical Hospital, Shtip, R. Macedonia 2 University Clinic of Endocrinology, Diabetes and Metabolic

Disorders, Medical Faculty, Skopje, R. Macedonia

${ }^{3}$ University Clinic of Cardiology, Medical Faculty,

Skopje, R. Macedonia ${ }^{4}$ Institute of Patophysiology and Nuclear Medicine, Medical Faculty, Skopje, R. Macedonia ${ }^{5}$ University Clinic of Cardiology, Medical Faculty, Skopje, R. Macedonia

Correspondence to: valentina.velkoska@yahoo.com

Received on Jun/5/2017 Accepted on Oct/11/2017 DOI: 10.20945/2359-3997000000052

\begin{abstract}
Objective: Treatment of subclinical hypothyroidism $(\mathrm{ScH})$, especially the mild form of $\mathrm{ScH}$, is controversial because thyroid hormones influence cardiac function. We investigate left ventricular systolic and diastolic function in $\mathrm{ScH}$ and evaluate the effect of 5-month levothyroxine treatment. Subjects and methods: Fifty-four patients with newly diagnosed mild $\mathrm{ScH}(4.2<\mathrm{TSH}<10.0 \mathrm{mU} / \mathrm{L})$ and 30 euthyroid subjects matched by age were analysed. Laboratory analyses and an echocardiography study were done at the first visit and after 5 months in euthyroid stage in patients with $\mathrm{ScH}$. Results: Compared to healthy controls, patients with $\mathrm{ScH}$ had a lower E/A ratio $(1.03 \pm 0.29$ vs. $1.26 \pm 0.36, \mathrm{p}<$ $0.01)$, higher $E / e^{\prime}$ sep. ratio $(7.62 \pm 2.29$ vs. $6.04 \pm 1.64, p<0.01)$, higher myocardial performance index (MPI) $(0.47 \pm 0.08$ vs. $0.43 \pm 0.07, p<0.05)$, lower global longitudinal strain (GLS) $(-19.5 \pm 2.3$ vs. $-20.9 \pm$ $1.7 \%, \mathrm{p}<0.05)$, and lower $\mathrm{S}$ wave derived by tissue Doppler imaging ( $0.077 \pm 0.013 \mathrm{vs.} 0.092 \pm 0.011 \mathrm{~m} / \mathrm{s}$, $\mathrm{p}<0.01)$. Levothyroxine treatment in patients with $\mathrm{ScH}$ contributed to higher $\mathrm{EF}(62.9 \pm 3.9$ vs. $61.6 \pm$ $4.4 \%, p<0.05)$, lower E/e' sep. ratio $(6.60 \pm 2.06$ vs. $7.62 \pm 2.29, p<0.01)$, lower MPI $(0.43 \pm 0.07$ vs. $0.47 \pm$ $0.08 \%, \mathrm{p}<0.01)$, and improved GLS $(-20.07 \pm 2.7$ vs. $-19.55 \pm 2.3 \%, \mathrm{p}<0.05)$ compared to values in ScH patients at baseline. Furthermore, in all study populations $(\mathrm{ScH}$ patients before and after levothyroxine therapy and controls), TSH levels significantly negatively correlated with $E F(r=-0.15, p<0.05)$, E/A ( $r$ $=-0.14, p<0.05), \mathrm{GLS}(r=-0.26, p<0.001)$, and S/TDI $(r=-0.22, p<0.01)$ and positively correlated with E/e' sep. $(r=0.14, p<0.05)$. Conclusion: Patients with subclinical hypothyroidism versus healthy individuals had subtle changes in certain parameters that indicate involvement of systolic and diastolic function of the left ventricle. Although the values of the parameters were in normal range, they were significantly different compared to $\mathrm{ScH}$ and the control group at baseline, as well as to the $\mathrm{ScH}$ groups before and after treatment. The results of our study suggest that patients with $\mathrm{ScH}$ must be followed up during treatment to assess improvement of the disease. Some of the echocardiography obtained parameters were reversible after levothyroxine therapy. Arch Endocrinol Metab. 2018;62(4):392-8
\end{abstract}

Keywords

Subclinical hypothyroidism; thyroid replacement therapy; systolic function; diastolic function

\section{INTRODUCTION}

ubclinical hypothyroidism $(\mathrm{ScH})$ is defined $\mathcal{Y}$ as a condition with a slight increase in serum concentration of thyrotropin (TSH) with normal values of circulating thyroid hormones, free thyroxine (FT4) and triiodothyronine (FT3).

The upper limit of TSH from which thyroid replacement therapy should start is still a topic of debate $(1,2)$. Treatment is generally recommended in severe $\mathrm{ScH}$ (TSH value above $10 \mathrm{mU} / \mathrm{L}$ ) (2-6). When the TSH value is less than $10 \mathrm{mU} / \mathrm{L}$, treatment may be indicated in relation to age, presence of goiter, or antithyroid antibodies. One meta-analysis (7) proposed starting with thyroid replacement therapy when TSH levels are above $7 \mathrm{mU} / \mathrm{L}$. Previous research (8) showed increased risk of atherosclerosis in patients with $\mathrm{ScH}$ at levels above $7 \mathrm{mU} / \mathrm{L}$.

Thyroid hormones influence cardiac function $(9,10)$. They regulate the transcription of structural and regulatory proteins in the cardiovascular system (11), predispose chronic inflammation and tissue changes (collagen alteration, dehydration), and also cause hemodynamic changes through their effect on smooth muscles in the arterial wall $(10,12)$. All these can alter cardiac function and together with atherosclerosis increase the risk of cardiovascular manifestations.

Research has revealed that substitution therapy with levothyroxine in $\mathrm{ScH}$ with TSH values above $10 \mathrm{mU} / \mathrm{L}$ could improve left ventricular (LV) function (13-16). Whether the same is true for mild $\mathrm{ScH}$ (TSH values less than $10 \mathrm{mU} / \mathrm{L}$ ) is unknown. 
The aim of the study was to evaluate the effect of levothyroxine therapy on LV systolic and diastolic function in patients with a mild form of $\mathrm{ScH}(4.2<$ TSH $<10.0 \mathrm{mU} / \mathrm{L}$ ) and after 5 months in euthyroid stage, using two-dimensional echocardiography, pulse Doppler, tissue Doppler, and two-dimensional speckle tracking imaging. An additional aim of the study was to predict which parameters derived by echocardiography can be used to monitor patients with $\mathrm{ScH}$.

\section{SUBJECTS AND METHODS}

\section{Patients}

The prospective study was conducted at the University Clinic of Endocrinology and the University Clinic of Cardiology in Skopje, R. Macedonia. The study included a control group and patients with a newly diagnosed mild form of $\mathrm{ScH}$. The control group consisted of 30 healthy euthyroid patients (normal FT4, FT3, and TSH of $0.2-$ $4.2 \mathrm{mU} / \mathrm{L}$ ). The criteria for a diagnosis of mild $\mathrm{ScH}$ were $4.2 \mathrm{mU} / \mathrm{L}<\mathrm{TSH}<10.0 \mathrm{mU} / \mathrm{L}$ with normal serum FT4 10.3-24.45 pmol/L and FT3 4.2-8.1 pmol/L. According to the recommendations of the British Thyroid Association, patients with $\mathrm{ScH}$ were placed on thyroid replacement therapy if one of the following criteria were present: at least three signs or symptoms of hypothyroidism, positive anti-TPO antibodies and positive anti-Tg antibodies, positive family history of thyroid disease, and thyroid enlargement or goiter on ultrasonography (17). The starting dose of L-thyroxine was $25 \mu \mathrm{g}$. TSH was measured every 8 weeks for dose adjustment. After 5 months in continuous euthyroid state, echocardiography was repeated. The euthyroid state was achieved with a mean dose of $60.8 \pm 19 \mu \mathrm{g}$ in mean duration of $7.5 \pm 2.2$ months. During a period of three years, 54 consecutive patients were included in the $\mathrm{ScH}$ group.

The control group was included to compare echocardiography parameters from the mild form of $\mathrm{SCH}$ at baseline.

\section{Exclusion criteria}

Patients with a previous history of thyroid disease receiving therapy for thyroid or cardiovascular function were not included. Patients who were cigarette smokers or who had cardiovascular disease, hypertension, hypothalamic-pituitary disease, depression, psychosis, bipolar disorders, diabetes, chronic pancreatitis, hepatic or renal disease, ovulatory dysfunction, infertility, or pregnancy were also not included.

\section{Ethical aspects}

All patients gave informed consent to participate in the study after careful explanation of the testing protocol. The study was conducted in accordance with the Declaration of Helsinki and approved by the Ethics Committee at the Medical Faculty in Skopje, R. Macedonia.

\section{METHODS}

At the first visit to the University Clinic of Endocrinology, blood samples for TSH, FT4, and FT3 were taken from all patients. At the same time, at the Outpatient Department of Cardiology Clinic, transthoracic echocardiography was done. Twodimensional (2D) echocardiography, pulsed wave (PW) Doppler, tissue Doppler imaging (TDI), and 2D speckle tracking echocardiography were used to assess left ventricular systolic and diastolic function.

\section{Laboratory tests}

All blood samples for thyroid hormones were collected from the antecubital vein between 08.00 and 09.00 a.m. TSH, FT4, and FT3 were determined by the supersensitive chemiluminescent immunoassay (Immulite 2000, Siemens Medical Solutions Diagnostics, Los Angeles, CA, USA). The functional sensitivity for TSH was $0.004 \mu \mathrm{IU} / \mathrm{mL}$, for FT4 $0.3 \mathrm{ng} / \mathrm{dL}$, and FT3 $0.4 \mathrm{ng} / \mathrm{dL}$.

\section{Echocardiographic measurements}

Standard assessments of LV dimensions and wall thickness were performed in standard views on commercially available equipment (Vivid 7, GE) according to the joint recommendations of the American Society of Echocardiography and the European Association of Cardiovascular Imaging (18). LV volume and ejection fraction were calculated using the biplane method of disks (modified Simpson's rule). Left atrial volume was derived by the biapical area-length method and indexed to body surface area (LAVI) (18). Diastolic parameters were obtained by pulsed Doppler by placing a sample volume at the point of touching the mitral leaflets: early mitral flow (E wave, in $\mathrm{m} / \mathrm{s}$ ) and late mitral flow (A wave, $\mathrm{m} / \mathrm{s}$ ), their ratio $(\mathrm{E} / \mathrm{A}, \mathrm{m} / \mathrm{s})$, and deceleration time $(\mathrm{DT}$, 
msec). Pulmonary venous flow was analysed using PW Doppler. We estimate peak systolic flow ( $\mathrm{S}$ wave, $\mathrm{m} / \mathrm{s}$ ), early diastolic flow (d wave, $\mathrm{m} / \mathrm{s}$ ), $\mathrm{s} / \mathrm{d}$ ratio, and atrial reversal flow $(\mathrm{Ar}, \mathrm{m} / \mathrm{s})$, including Ar-A duration (msec) difference (19). PW TDI was performed in the apical 4-chamber view to assess annular early and late diastolic velocities (19). The recording was performed at a sweep speed of $100 \mathrm{~mm} / \mathrm{s}$ at end-expiratory apnea. The septal, lateral, and average early diastolic velocities were measured, then the ratio of mitral flow $\mathrm{E}$ wave and TDI e' wave (E/e') for each of these annular velocities was calculated. By TDI we also estimate $S$ wave like a maximal systolic velocity $(\mathrm{m} / \mathrm{sec})$ which is a parameter for evaluation of longitudinal systolic function (20). With the values of isovolumetric contractile time (IVCT, msec), isovolumetric relaxation time (IVRT, msec), and ejection time (ET, msec) derived by TDI, we calculated the myocardial performance index (MPI), which is a parameter for global left systolic function. We use the formula MPI = IVCT + IVRT / ET. The average of three consecutive cardiac cycles was taken for measurement of each echocardiographic index.

Global and regional peak systolic longitudinal strain was assessed from apical 2-chamber, 4-chamber, and long-axis views using speckle tracking analysis (21). Recordings were processed using an acoustic tracking software (EchoPac, GE, USA), allowing offline semiautomated analysis of speckle-based strain. All images were recorded with a high frame rate $(>50$ frames/s). A semiautomatic myocardial tracking system was used, with manual correction of the endocardial border in end-systole and manual adjustment of the region of interest, if needed. The end of systole was defined as the point of aortic valve closure. The software automatically detected the frame-to-frame movement of the natural ultrasound reflecting markers (speckles) on standard ultrasonic images in two dimensions. The LV was divided into 17 segments, and each segment was analysed individually. Only myocardial segments considered to be of adequate quality by both the automatic system and the operator were included in the analysis. Global longitudinal strain for the LV was automatically provided as the average value of the regional peak systolic longitudinal strain of the three apical views by the software.

\section{Statistical analysis}

Categorical parameters were summarized as percentages and continuous parameters as mean $\pm \mathrm{SD}$. The normal distribution of variables was verified with the ShapiroWilk test. As the distribution was normal, Student's independent $t$-test was used for the comparison of the quantitative data between the control group and the $\mathrm{ScH}$ group at baseline. Student's paired t-test was used for the comparison of the quantitative data before and after the levothyroxine therapy in the $\mathrm{ScH}$ group. For the comparison of categorical variables the chisquare test, Yates correction was used. The correlation between the tested parameters was determined using the Pearson correlation. All data analysis was performed using SPSS version 14.0 (IBM SPSS, Inc., Chicago, Illinois) and $\mathrm{p}$ value $\leq 0.05$ was considered significant.

\section{RESULTS}

Patients and normal controls were well matched for age, sex, BMI, and BSA. Heart rate was similar in both groups, but significantly increased in the $\mathrm{ScH}$ group after the levothyroxine treatment. The systolic blood pressure was significantly higher in the $\mathrm{ScH}$ group at baseline than in the control group, but the treatment with levothyroxine didn't make any changes. The diastolic blood pressure was similar in both groups, without difference after levothyroxine treatment. As expected, TSH levels were significantly higher in the $\mathrm{ScH}$ group than in the control group. FT4 and FT3 levels, although in the reference range, were significantly lower in the $\mathrm{ScH}$ group at baseline than in the control group. Interestingly, after the thyroid substitution therapy, FT4 and FT3 levels significantly increased in the $\mathrm{ScH}$ group (Table $\mathrm{l}$ ).

The LV diameters and volumes were similar in both groups, $\mathrm{ScH}$ at baseline and control groups. Overall, only EF (although in referent range in all analysed groups) statistically significantly increased in the $\mathrm{ScH}$ group after the levothyroxine therapy (Table 2).

The results from echocardiography (systolic and diastolic parameters) in all analysed groups were in normal range, but some of them were statistically different compared to $\mathrm{ScH}$ and the control group at baseline, as well as to the $\mathrm{ScH}$ groups before and after treatment. The transmitral E/A ratio was lower and E/e' sep. ratio was higher in the $\mathrm{ScH}$ group at baseline than in the control group. The E/e' sep. ratio significantly decreased in the $\mathrm{ScH}$ group after levothyroxine therapy. The MPI was higher in the $\mathrm{ScH}$ group at baseline than in the control group and significantly decreased after levothyroxine therapy. The GLS was significantly 
reduced in the $\mathrm{ScH}$ group at baseline in comparison to the control group and significantly improved after levothyroxine therapy. The $S$ wave estimated from TDI was significantly lower in the $\mathrm{ScH}$ group at baseline

Table 1. Demographic, clinical, and hormonal parameters of study population

\begin{tabular}{|c|c|c|c|c|}
\hline & Control group $(n=30)$ & Baseline ScH $(n=54)$ & ScH after 5 months $(n=54)$ & Statistical significance \\
\hline Age (years) & $39.3 \pm 11.7$ & $43.1 \pm 12.4$ & & NS \\
\hline $\operatorname{Sex}(m: f)$ & $3: 27$ (10\%) & $2.52(3.7 \%)$ & & NS \\
\hline BMI $\left(\mathrm{kg} / \mathrm{m}^{2}\right)$ & $24.3 \pm 3.0$ & $26.7 \pm 4.2$ & $25.7 \pm 4.2$ & NS \\
\hline $\mathrm{BSA}\left(\mathrm{m}^{2}\right)$ & $1.78 \pm 0.15$ & $1.79 \pm 0.17$ & $1.78 \pm 0.16$ & NS \\
\hline $\mathrm{HR}(\mathrm{bpm})$ & $76.4 \pm 9.1$ & $73.4 \pm 9.8$ & $77.1 \pm 9.9$ & $p<0.05^{b}$ \\
\hline Systolic BP (mmHg) & $107.3 \pm 28.4$ & $123.3 \pm 16.4$ & $122.1 \pm 14.2$ & $p<0.05^{a, c}$ \\
\hline Diastolic BP (mmHg) & $77 \pm 13.4$ & $80.0 \pm 9.3$ & $79.2 \pm 8.4$ & NS \\
\hline TSH mU/L & $1.7 \pm 1.05$ & $8.1 \pm 1.3$ & $2.8 \pm 2.6$ & $p<0.001^{a, b}$ \\
\hline FT4 pmol/L & $15.4 \pm 2.2$ & $12.3 \pm 2.0$ & $15.2 \pm 2.6$ & $p<0.01^{a, b}$ \\
\hline $\mathrm{FT} 3 \mathrm{pmol} / \mathrm{L}$ & $5.2 \pm 2.1$ & $4.5 \pm 1.1$ & $6.4 \pm 3.3$ & $p<0.05^{a, b}$ \\
\hline
\end{tabular}

Displayed results are average \pm std deviation and percentages. Comparisons between the groups were performed by Student's $t$-test (independent and dependent) for continuous variables and $\chi 2$ test for categorical variables.

a Statistical significance for controls vs. baseline ScH; ${ }^{b}$ statistical significance for baseline ScH vs. ScH after 5 months; c statistical significance for controls vs. ScH after 5 months.

BMI: body mass index; BSA: body surface area; HR: heart rate; BP: blood pressure; NS: no significance.

Table 2. Echocardiographic parameters of left ventricular function in the study population

\begin{tabular}{|c|c|c|c|c|}
\hline & Control group $(n=30)$ & Baseline ScH $(n=54)$ & ScH after 5 months $(n=54)$ & Statistical significance \\
\hline LA (mm) & $31.7 \pm 3.1$ & $31.3 \pm 3.9$ & $31.7 \pm 3.9$ & NS \\
\hline LAVI (ml/m²) & $24.4 \pm 4.31$ & $21.9 \pm 5.77$ & $20.7 \pm 5.43$ & NS \\
\hline LVEDD (mm) & $46.0 \pm 4.8$ & $46.4 \pm 4.3$ & $45.6 \pm 4.1$ & NS \\
\hline LVED vol $\left(\mathrm{mL}^{3}\right)$ & $79.1 \pm 11.9$ & $81.7 \pm 18.4$ & $79.0 \pm 18.6$ & NS \\
\hline LVES vol $\left(\mathrm{mL}^{3}\right)$ & $31.3 \pm 7.0$ & $31.6 \pm 7.8$ & $30.6 \pm 6.5$ & NS \\
\hline $\mathrm{EF}(\%)$ & $62.8 \pm 2.3$ & $61.6 \pm 4.4$ & $62.9 \pm 3.9$ & $p<0.05^{b}$ \\
\hline IVS (mm) & $10.4 \pm 1.1$ & $10.8 \pm 0.9$ & $10.8 \pm 1.0$ & NS \\
\hline PW (mm) & $8.7 \pm 1.2$ & $8.7 \pm 1.2$ & $8.7 \pm 1.1$ & NS \\
\hline $\mathrm{E} / \mathrm{A}(\mathrm{m} / \mathrm{sec})$ & $1.26 \pm 0.36$ & $1.03 \pm 0.29$ & $1.09 \pm 0.34$ & $\mathrm{p}<0.01^{\mathrm{a}, \mathrm{c}}$ \\
\hline DT(msec) & $156.8 \pm 29.7$ & $167.9 \pm 38.6$ & $158.5 \pm 32.2$ & NS \\
\hline E/e' sep. & $6.04 \pm 1.64$ & $7.62 \pm 2.29$ & $6.60 \pm 2.06$ & $\mathrm{p}<0.01^{\mathrm{a}, \mathrm{b}}$ \\
\hline E/e' lat. & $6.08 \pm 1.24$ & $6.35 \pm 1.62$ & $6.03 \pm 1.74$ & NS \\
\hline E/e' average & $6.06 \pm 1.24$ & $6.98 \pm 1.9$ & $6.74 \pm 1.7$ & NS \\
\hline IVCT (msec) & $60.04 \pm 10.9$ & $64.14 \pm 13.4$ & $60.29 \pm 12.7$ & NS \\
\hline IVRT (msec) & $66.39 \pm 8.3$ & $67.27 \pm 13.7$ & $65.0 \pm 12.8$ & NS \\
\hline MPI & $0.43 \pm 0.07$ & $0.47 \pm 0.08$ & $0.43 \pm 0.07$ & $p<0.05^{\mathrm{a}} ; \mathrm{p}<0.01^{\mathrm{b}}$ \\
\hline$s / d$ & $1.26 \pm 0.11$ & $1.26 \pm 0.16$ & $1.25 \pm 0.22$ & NS \\
\hline GLS (\%) & $-20.9 \pm 1.7$ & $-19.55 \pm 2.3$ & $-20.07 \pm 2.7$ & $p<0.001^{a} ; p<0.05^{b}$ \\
\hline $\mathrm{S} / \mathrm{TDI}(\mathrm{m} / \mathrm{sec})$ & $0.092 \pm 0.011$ & $0.077 \pm 0.013$ & $0.078 \pm 0.01$ & $p<0.01^{a, c}$ \\
\hline Ar-A & $-18.87 \pm 10.78$ & $-25.2 \pm 16.1$ & $-23.4 \pm 9.1$ & NS \\
\hline
\end{tabular}

Displayed results are average \pm std deviation and percentages. Comparisons between the groups were performed by Student's $t$-test (independent and dependent) for continuous variables and $\chi^{2}$ test for categorical variables.

a Statistical significance for controls vs. baseline ScH; b Statistical significance for baseline ScH vs. ScH after 5 months; ' statistical significance for controls vs. ScH after 5 months

LA: left atrial systolic diameter; LAVI: left atrial volume index; LVEDD: end-diastolic diameters; PW: the left ventricular posterior wall; IVS: interventricular septum thickness; LVESV: left ventricular end-systolic volume; LVEDV: left ventricular end-diastolic volume; EF: ejection fraction; E/A: ratio between transmitral early and late diastolic peak flow velocities; A dur: duration of the atrial contraction; DT: time between E velocity deceleration time to the baseline; S wave obtained by TDI, maximal systolic flow velocity; IVCT: isovolumetric contraction time; IVRT: isovolumetric relaxation time; MPI: myocardial performance index; s: systolic velocity of the pulmonary veins; d: diastolic velocity of the pulmonary veins; their ratio (s/d); Ar: retrograde pulmonary venous flow during the atrial contraction-atrial reversal; A-Ar: difference in time of duration of the A wave from transmitral flow by PW and duration of the Ar wave from pulmonary vein flow; GLS: global longitudinal strain. 
than in the control group, without changes after the levothyroxine therapy (Table 2). Analysing how many patients had diastolic dysfunction, according to new guidelines for the evaluation of diastolic function by echocardiography, showed that there were only three patients with $\mathrm{ScH}(22)$. In all three patients diastolic dysfunction was reversible after thyroid replacement therapy.

Considering the entire study population, the TSH levels (before and after levothyroxine therapy) significantly negatively correlated with $\mathrm{EF}(\mathrm{r}=-0.15$, $\mathrm{p}<0.05)$, E/A ratio $(\mathrm{r}=-0.14, \mathrm{p}<0.05)$, GLS $(\mathrm{r}=$ $-0.26, \mathrm{p}<0.001)$, and S/TDI $(\mathrm{r}=-0.22, \mathrm{p}<0.01)$ and positively correlated with E/e' sep. $(\mathrm{r}=0.14, \mathrm{p}<$ $0.05)$.

\section{DISCUSSION}

The results of the study presented subtle changes in the LV systolic and diastolic function which were reversible after thyroid replacement therapy. Although the values of the echocardiography parameters were in normal range in all analysed groups (control, $\mathrm{ScH}$ at baseline, and $\mathrm{SCH}$ after treatment), there were statistically significant differences between some parameters compared to the control and $\mathrm{ScH}$ group at baseline, as well as to the $\mathrm{ScH}$ group before and after treatment.

Our results show that the $\mathrm{ScH}$ group at baseline had statistically significantly higher values for systolic blood pressure. This result is similar to the results in one meta-analysis published in 2014. The study includes the analysis of 20 studies and found a slight increase in systolic blood pressure in patients with $\mathrm{ScH}$ versus the control group (23). Systolic blood pressure did not decrease significantly after the levothyroxine treatment. The average value for systolic blood pressure in the $\mathrm{ScH}$ group at baseline was normal $(123.3 \pm 16.4 \mathrm{mmHg})$, so the thyroid replacement therapy probably had no clinical significance in reducing its value. Thus, we can conclude that $\mathrm{ScH}$ had no significant impact on the arterial blood pressure, in contrast to what is already known about clinical hypothyroidism. Therefore, we do not expect the thyroid replacement therapy to significantly decrease the already normal values for systolic blood pressure.

Heart rate statistically significantly increased after thyroid replacement therapy. These changes are consistent with the known mechanism of action of thyroid hormones. From a clinical point of view, the increase in heart rate after treatment was still in the normal range $(77.1 \pm 9.9$ minute $)$, but there was statistical significance. None of the patients after treatment had tachycardia or arrhythmia.

At baseline, echocardiographic parameters of LV function were not significantly different between the control and the $\mathrm{ScH}$ group, which were similar with results from other studies (15,24-28). Five months of levothyroxine therapy statistically significantly increased the EF. Only a small (1.3\%) increase in EF was sufficient to make EF equal to the value $(62.9 \pm 3.9 \%)$ as in the control group. In the study of Ilic and cols. (29), oneyear therapy with levothyroxine showed results similar to ours. It is important to mention that all studies (including ours) that analyse the EF in patients with $\mathrm{ScH}$ have normal values for $\mathrm{EF}$.

The parameter $S$ derived from TDI, which is a parameter toassess systolic function of LV, wasstatistically significantly lower in the $\mathrm{ScH}$ group compared to the control group. This proves the abnormal longitudinal systolic function of $\mathrm{LV}$ in $\mathrm{ScH}$, which is first affected in LV systolic dysfunction (30,31). The parameter S/ TDI did not recover after treatment, but there was statistically significant correlation between TSH and S/TDI. More aggressive treatment for lowering TSH value may result in statistically significant changes in S/TDI. Completely identical results were shown in the study of Ilic and cols. (29). The average age in the study of Ilic and cols. (29) is similar to ours, but they analysed only women aged less than 45 years. Probably studies with a large number of patients involving only women in reproductive age are needed to confirm the impact of $\mathrm{ScH}$ on $\mathrm{S}$ wave derived from TDI.

Results for MPI showed deterioration in global systolic and diastolic function of the $\mathrm{LV}$ in $\mathrm{ScH}$, and its reversibility after thyroid replacement therapy. Our results were consistent with those from other clinical studies $(24,25,29)$. The average values of TSH in those studies are similar to this study. There was no statistically significant correlation between TSH and MPI. The lack of correlation between TSH and MPI may be due to small changes in the value of MPI that occur at higher values of TSH.

Global longitudinal strain is considered more sensitive than EF in assessing LV global systolic function, especially when the EF is normal, in favour of subclinical LV dysfunction. Values of GLS in the control group and $\mathrm{ScH}$ group at baseline were within the normal range, but still with statistically significantly different 
values in the $\mathrm{ScH}$ group. GLS significantly improved after the levothyroxine therapy. TSH significantly negatively correlated with GLS. Two studies examined GLS in $\mathrm{ScH}$, and both of them showed results similar to ours $(29,32)$.

The results from Doppler transmitral flow and velocities estimated by TDI showed changes in some parameters which are defined as parameters for diastolic function assessment. Although the values of some parameters were in the normal range, there is a statistically significant difference between the values of the control and $\mathrm{ScH}$ groups. This is shown by statistically significantly lower E/A ratio, and higher E/e' sep. ratio in the $\mathrm{ScH}$ group compared to the control group.

After 5 months of euthyroid state, the $\mathrm{E} / \mathrm{A}$ ratio did not increase significantly. In a study by Yazici and cols. (25) the E/A ratio was statistically significantly lower in patients with $\mathrm{ScH}$ compared to the control group. In the same study, the ratio increased significantly after 6 months of euthyroid state and continued to increase after 12 months of euthyroid state. A study by Erkan and cols. (33) showed results similar to ours. Therefore, a longer euthyroid state or more aggressive treatment for lowering TSH may be required to achieve a statistically significant increase in the $\mathrm{E} / \mathrm{A}$ ratio, after treatment. At the end of the study the average TSH value was 2.8 $\pm 2.6 \mathrm{mU} / \mathrm{L}$. In the assessment of diastolic function the $\mathrm{E} / \mathrm{e}$ ' sep. ratio is a more sensitive parameter than the $\mathrm{E} / \mathrm{e}$ ' lat. ratio. A statistically significant difference in the $\mathrm{E} / \mathrm{e}$ ' sep. ratio, but not in the $\mathrm{E} / \mathrm{e}$ ' lat. Ratio, was found in other studies $(24,28)$. Three patients in the $\mathrm{ScH}$ group had diastolic dysfunction, which was reversible after thyroid replacement therapy. Diastolic dysfunction is mainly attributed to $\mathrm{ScH}$ because other potential causes of diastolic dysfunction (hypertension, diabetes mellitus) were excluded in this study. Parameters which measured diastolic dysfunction can be applied to all patients with $\mathrm{ScH}$ and also to follow them during treatment.

Statistically significant correlations between TSH and analysed parameters were weak $(\mathrm{r}<0.5)$. The weak correlation coefficient may be due to higher TSH values at the end of the study. The $r$ values were lower for correlations with diastolic parameters. Probably systolic parameters are more sensitive on L-T4 treatment, and diastolic parameters need a longer period of treatment.

Summarizing the results, $\mathrm{ScH}$ did not cause cardiac failure by itself, but thyroid substitution therapy improves some parameters of LV function. We analysed only patients with mild $\mathrm{ScH}$, which means rapid detection of thyroid dysfunction. If $\mathrm{ScH}$ is detected later, according to the correlations, we expected worsening of LV parameters.

There are some limitations in this study. The design is not that of a blind or double-blind study which includes L-thyroxine and placebo. We followed the parameters of systolic and diastolic function, but we did not directly observe cardiovascular morbidity and mortality, which requires very long-term monitoring of patients.

The advantages of the study compared to previous similar studies are the inclusion of young people with no risk factors for cardiovascular disease which can influence systolic and diastolic parameters, and the inclusion of patients with mild $\mathrm{ScH}$. Thus, this study confirmed the benefit of levothyroxine treatment in patients with $\mathrm{ScH}$ with lower values of TSH. Today, when there is a lack of recommendations for treatment of mild $\mathrm{ScH}$, this study moves the limits for initiation with treatment from the lower values of TSH.

In conclusion, patients with $\mathrm{ScH}$ versus healthy individuals had subtle changes in certain parameters that indicate involvement of systolic and diastolic function of the $\mathrm{LV}$ in $\mathrm{ScH}$. Although the values of the parameters were in normal range, they were significantly different compared to $\mathrm{ScH}$ and the control group at baseline, as well as to the $\mathrm{ScH}$ groups before and after treatment. The results of our study suggest that the patients with $\mathrm{ScH}$ deserve to be followed up during treatment.

Disclosure: no potential conflict of interest relevant to this article was reported.

\section{REFERENCES}

1. UK guidelines for the use of thyroid function tests. 2006. Available from: www.british-thyroid-association.org/TFT_guideline_final_version_July_2006.pdf. Accessed on: Jul 10, 2009.

2. Garber JR, Cobin RH, Gharib H, Hennessey JV, Klein I, Mechanick Jl, et al.; American Association of Clinical Endocrinologists and American Thyroid Association Taskforce on Hypothyroidism in Adults. Clinical practice guidelines for hypothyroidism in adults: cosponsored by the American Association of Clinical Endocrinologists and the American Thyroid Association. Endocr Pract. 2012;18(6):988-1028.

3. Cooper DS. Clinical practice. Subclinical hypothyroidism. N Engl J Med. 2001;345(4):260-5.

4. Chu JW, Crapo LM. The treatment of subclinical hypothyroidism is seldom necessary. J Clin Endocrinol Metab. 2001;86(10):4591-9.

5. McDermott MT, Ridgway EC. Subclinical hypothyroidism is mild thyroidfailure and should be treated. J Clin Endocrinol Metab. 2001;86(10):4585-90. 
6. Garber JR, Cobin RH, Gharib H, Hennessey JV, Klein I, Mechanick $\mathrm{JI}$, et al.; American Association of Clinical Endocrinologists and American Thyroid Association Taskforce on Hypothyroidism in Adults. Clinical practice guidelines for hypothyroidism in adults: cosponsored by the American Association of Clinical Endocrinologists and the American Thyroid Association. Thyroid. Thyroid. 2012;22:1200-35.

7. Rodondi N, den Elzen WPJ, Bauer DC, Cappola AR, Razvi S, Walsh JP, et al.; Thyroid Studies Collaboration. Subclinical hypothyroidism and the risk of coronary heart disease and mortality. JAMA. 2010;304(12):1365-74.

8. Velkoska Nakova V, Bosevski M, Dimitrovski Ch, Krstevska B. Subclinical hypothyroidism and risk to carotid atherosclerosis. Arq Bras Endocrinol Metab. 2011;55(7):475-80.

9. Kahaly GJ. Cardiovascular and atherogenic aspects of subclinical hypothyroidism. Thyroid. 2000;10(8):665-79.

10. Biondi B, Palmieri EA, Lombardi G, Fazio S. Subclinical hypothyroidism and cardiac function. Thyroid. 2002;12(6):505-10.

11. Aksoy D, Cinar N, Harmanci A, Karakaya A, OkanYildiz B, Usman $A$, et al. Serum resistin and high sensitive CRP levels in patients with subclinical hypothyroidism before and after L-thyroxine therapy. Med Sci Monit. 2013;19:210-5.

12. Klein I. Thyroid hormone and the cardiovascular system. Am J Med. 1990;88(6):631-7.

13. Biondi B, Fazio S, Palmieri EA, Carella C, Panza N, Cittadini A, et al. Left ventricular diastolic dysfunction in patients with subclinical hypothyroidism. J Clin Endocrinol Metab. 1999;84(6):2064-7.

14. Monzani F, DiBello V, Caraccio N, Bertini A, Giorgi D, Giusti C, et al. Effect of levothyroxine on cardiac function and structure in subclinical hypothyroidism: a double blind, placebo-controlled study. J Clin Endocrinol Metab. 2001;86(3):1110-5.

15. Vitale G, Galderisi M, Lupoli GA, Celentano A, Pietropaolo I, Parenti N, et al. Left ventricular myocardial impairment in subclinical hypothyroidism assessed by a new ultrasound tool: pulsed tissue Doppler. J Clin Endocrinol Metab. 2002;87(9):4350-5.

16. Brenta G, Mutti LA, Schnitman M, Fretes O, Perrone A, Matute $\mathrm{ML}$. Assessment of left ventricular diastolic function by radionuclide ventriculography at rest and exercise in subclinical hypothyroidism, and its response to L-thyroxine therapy. Am J Cardiol. 2003;91(11):1327-30.

17. British Ministry of Health - recommendations. Available from: http://www.bcguidelines.ca/guideline_thyroid.html. Accessed on: Feb. 23, 2012.

18. Lang RM, Badano LP, Mor-Avi V, Afilalo J, Armstrong A, Ernande $L$, et al. Recommendations for Cardiac Chamber Quantification by Echocardiography in Adults: An Update from the American Society of Echocardiography and the European Association of Cardiovascular Imaging. Eur Heart J Cardiovasc Imaging. 2015;16(3):233-71.

19. Nagueh SF, Appleton CP, GillebertTC, Marino PN, Oh JK, Smiseth $\mathrm{OA}$, et al. Recommendations for the evaluation of left ventricular diastolic function by echocardiography. Eur J Echocardiogr. 2009;10(2):165-93.

20. Chaha NS, Lim TK, Jain P, Chambers JC, Kooner JS, Senior R. Normative reference values for the tissue Doppler imaging pa- rameters of left ventricular function: a population-based study. Eur J Echocardiogr. 2010;11(1):51-6.

21. Mor-Avi V, Lang RM, Badano LP, Belohlavek M, Cardim NM, Derumeaux $G$, et al. Current and evolving echocardiographic techniques for the quantitative evaluation of cardiac mechanics: ASE/ EAE consensus statement on methodology and indications endorsed by the Japanese Society of Echocardiography. J Am Soc Echocardiogr. 2011;24(3):277-313.

22. Naguch SE, Smiseth OA, Appleton CP, Byrd BF, Dokainish H, Edvardsen T, et al.: Recommendations for the Evaluation of Left Ventricular Diastolic Function by Echocardiography: An Update from the American Society of Echocardiography and the European Association of Cardiovascular Imaging. J Am Soc Echocardiogr. 2016;29(4):277-314.

23. YeY, Xie H, Zeng Y, Zhao X, Tian Z, Zhang S. Association between subclinical hypothyroidism and blood pressure--a meta-analysis of observational studies. Endocr Pract. 2014;20(2):150-8.

24. Öner FA, Yurdakul S, Öner E, Arslanta囚 MK, Usta M, Ergüney M. Evaluation of ventricular functions using tissue Doppler echocardiography in patients with subclinical hypothyroidism. Turk Kardiyol Dern Ars. 2011;39(2):129-36.

25. Yazici M, Gorgulu S, Sertbas Y, Erbilen E, Albayrak S, Yildiz O, et al. Effects of thyroxin therapy on cardiac function in patients with subclinical hypothyroidism: index of myocardial performance in the evaluation of left ventricular function. Int J Cardiol. 2004;95(23):135-43.

26. Franzonia F, Galettaa F, Fallahia P, Tocchini L, Merico G, Braccini $L$, et al. Effect of L-thyroxine treatment on left ventricular function in subclinical hypothyroidism. Biomed Pharmacother. 2006;60(8):431-6.

27. Oztutk S, Alcelik A, Ozyasar M, Dikbas O, Ayhan S, Ozlu F, at al. Evaluation of left ventricular systolic asynchrony in patients with subclinical hypothyroidism. Cardiol J. 2012;19(4):374-80.

28. Ozturk S, Dikbas O, Baltaci D, Ozyasar M, Erdem A, Eyhan SS, et al. Evaulation of atrial conduction abnormalities and left atrial mechanical functions in patients with subclinical thyroid disorders. Endokrynol Pol. 2012;63(4):286-93.

29. Ilic S, Tadic M, Ivanovic B, Caparevic Z, Trbojevic B, Celic V. Left and right ventricular structure and function in subclinical hypothyroidism: the effects of one-year levothyroxine treatment. Med Sci Monit. 2013 Nov 10;19:960-8.

30. Ho CY, Solomon SD. A clinician's guide to tissue Doppler imaging. Circulation. 2006;113(10):e396-8.

31. Gillam L, Otto CM. Advanced approaches in echocardiography. Rio de Janeiro: Elsevier. 2012.

32. Sunbul M, Durmus E, KivrakT, Yildiz H, Kanar BG, Ozben B, et al. Left ventricular strain and strain rate by two-dimensional speckle tracking echocardiography in patients with subclinical hypothyroidism. Eur Rev Med Pharmacol Sci. 2013;17(24):3323-8.

33. Erkan G, Erkan AF, Cemri M, Karaahmetoglu S, Cesur M, Cengel A. The evaluation of diastolic dysfunction with tissue Doppler echocardiography in women with subclinical hypothyroidism and the effect of L-thyroxine treatment on diastolic dysfunction: a pilot study. JThyroid Res. 2011;2011:654304. 